\title{
BMJ Open Rehabilitation following flexor tendon injury to the hand in African countries: a study protocol for a scoping review
}

\author{
Martin Marume (i) , ${ }^{1,2}$ Susan De Klerk, ${ }^{3}$ Lee-Ann Jacobs-Nzuzi Khuabi ${ }^{4}$
}

To cite: Marume M, De Klerk S, Khuabi L-AJ-N. Rehabilitation following flexor tendon injury to the hand in African countries: a study protocol for a scoping review. BMJ Open 2021;11:e045260. doi:10.1136/ bmjopen-2020-045260

- Prepublication history for this paper is available online. To view these files, please visit the journal online (http://dx.doi org/10.1136/bmjopen-2020045260).

Received 25 September 2020 Revised 06 April 2021 Accepted 09 April 2021

Check for updates

(C) Author(s) (or their employer(s)) 2021. Re-use permitted under CC BY-NC. No commercial re-use. See rights and permissions. Published by BMJ.

${ }^{1}$ Occupational Therapy, Stellenbosch UniversityTygerberg Campus, Cape Town, Western Cape, South Africa

${ }^{2}$ Occupational Therapy, Katutura State Hospital, Windhoek, Khomas, Namibia

${ }^{3}$ Occupational Therapy, Stellenbosch University

Faculty of Medicine and Health Sciences, Cape Town, Western Cape, South Africa

${ }^{4} 0$ ccupational Therapy, Stellenbosch University Department of Medicine, Cape Town, Western Cape, South Africa

Correspondence to

Martin Marume;

martin060188@gmail.com

\section{ABSTRACT}

Quality of life is enhanced by engagement in meaningful activities and participation using our hands. In African countries, people rely predominantly on the use of their hands to engage in economic productive activities, including agricultural, fishing, mining and construction, that are largely performed by machines in high-income contexts. Anecdotal evidence suggests a high incidence of flexor tendon injuries that are managed using protocols that were adopted from high-income countries and implemented without considering contextual differences. African therapists use discretion in selecting protocols thereby presenting inconsistency in tendon management. This result in challenges with ascertaining the most effective protocol, factors that influence protocols and the extent of evidence about flexor tendon rehabilitation in Africa. Therefore, this scoping review aims to provide evidence currently available on the rehabilitation of flexor tendons in African countries. This will synthesise the advantages and disadvantages of the current protocols and make proposals that are contextually relevant and cost-effective for rehabilitation of tendon injuries. Methods and analysis The research will follow the scoping review methodological framework developed by Arksey and 0'Malley (2005). The search strategy was developed and will be used to retrieve articles from eight databases. Further literature will be searched in the bibliography of the identified eligible articles. Grey literature will be searched in scientifically reliable websites, organisations and other sources. Articles will be reviewed by two independent researchers and opinion will be sought from a third reviewer when disagreement prevails on the inclusion quality of an article. All relevant articles that meet the criteria will be analysed using Weft QDA.

Ethics and dissemination The scoping review paper will be discussed with local therapists. Thereafter, findings will be published in the year 2021 and sent to rehabilitation associations in respective African countries.

\section{INTRODUCTION}

Tendon injuries significantly impact quality of life due to associated loss of hand function. This impact is profound in the African context where the majority of livelihoods may depend on people performing manual work and the use of machines/technology may be limited. The hand is considered to be a multipurpose

\section{Strengths and limitations of this study}

- The search strategy for the protocol will be developed with the help of the expert librarian to verify the terms and databases to be used considering all languages and validated by expert therapists to whom the researcher has access.

- The search strategy will include databases such as the Cochrane library, CINAHL-EBSCOhost, Academic Search Premier, Health Source Nursing (academic edition), Google Scholar, PubMed Medline, Scopus, Web of Science, African Journal Online, Sabinet African Journal, African Journal Archive, AfricaWide, reference lists and grey literature sources to ensure that all relevant literature is captured.

- A review of articles will be performed separately by two people and any disagreements will be mediated by a third reviewer so as to ensure a consistent and rigorous application of the inclusion and exclusion criteria.

- The grey literature might be limited due to delay in response from authors as a result of the burden placed on academia by the COVID-19 pandemic.

- The focus of the study is limited to rehabilitation protocols for flexor tendon injuries and does not include other pathologies that may affect hand function.

instrument in meeting social and economic responsibilities through skilled and unskilled manual labour. ${ }^{12}$ Loss of hand function, as can be brought about by flexor tendon injury, could threaten livelihood. Despite the importance of hand function in African countries, there is a perceived lack of evidence to ascertain the effectiveness of flexor tendon rehabilitation protocols in the African setting.

Prevalence studies to quantify the burden of flexor tendon injuries within Africa are sparse. This could be as a result of a lack of standardised recording systems that would limit the opportunity to collate and report such data. Ihekire et al however reported the prevalence of severe hand soft tissue injuries (including flexor tendon injuries) within the context of Ethiopia to be $37.5 \% .^{3}$ In addition, Stewart et al concluded that traumatic hand 
injury accounted for one-third of all traumatic injuries seen at public hospitals within South Africa. ${ }^{4}$ Experiential evidence from a surgical hospital in Khomas Region of Namibia, Intermediate Hospital Katutura also suggests a high prevalence. The occupational therapy department at the said Namibian hospital received an average of 17 new cases of flexor tendon injuries per month from the year 2016 to 2019. Furthermore, anecdotal evidence from some southern African countries suggests that public sectors have high numbers of patients with multiple injuries including flexor tendon injuries.

The perceived high burden of flexor tendon injury could be attributed to a number of factors that may include poor governance and political instability. This environment promotes and escalates violent behaviour that lead to cases of traumatic hand injuries including flexor tendon injuries. ${ }^{5}$ Moreover, motor vehicle accidents, poor ergonomic laws and the nature of work increase the risk of traumatic hand injury. Persons engage in economic productivity using hazardous handheld tools in agriculture, mining, construction and fishing that predispose the hand to injury. ${ }^{5-7}$

Even though flexor tendon injuries are expected to be common, there is a perceived lack of standardisation of flexor tendon rehabilitation in the African context. Therapists rely on approaches adopted from highincome countries; implemented differently in relation to prevailing contextual characteristics.

\section{Relevant literature}

Flexor tendon injury management begins with surgery, leading to a selection of rehabilitative approaches to be used for 12 weeks. However, contextual factors influence the management and outcome of flexor tendon injuries. African countries experience severe shortage of medical and human resources that may delay flexor tendon management. An example is the South Africa under-resourced public healthcare system that serves almost $84 \%$ of the population with $17 \%$ of the resources and yet, public healthcare in South Africa is considered to be better than in most African countries. ${ }^{8-10}$ Time and resource-consuming intricate flexor tendon rehabilitation and protocols are unlikely to be adhered to within the limitations of public healthcare in Africa.

Furthermore, poor transport infrastructure affects access to specialised health facilities that are situated mostly in urban areas. ${ }^{811} 12$ Additionally, only a few therapists and doctors are specialised in management following injury to the hand. ${ }^{81113}$ These factors impact the rehabilitation of persons with flexor tendon injury, a condition that may be worsened by inherent complications that interfere with tendon excursion and gliding.

Gliding exercises are the cornerstone of rehabilitation following flexor tendon injury and repair. Gliding exercises prevent tendon adherence and improve excursion, however, these can only be introduced after timely and skilled surgical procedure to create a strong stable bond between ends of a ruptured tendon. ${ }^{14}$ It is advisable to repair the tendon within 2 weeks using four-strand or sixstrand suturing techniques while avoiding bulkiness at the repair site. ${ }^{11}$ Delayed repairs are a reality in the African context. In addition, tendons may be repaired poorly by inexperienced and unspecialised surgeons using either two-strand or four-strand suturing. Poorly performed suturing can lead to gapping, tendon rupture and bulkiness. ${ }^{11}$ This therefore hinders the timeous introduction of flexor tendon gliding exercises, as is recommended in the available flexor tendon rehabilitation approaches, derived from healthcare settings in high-income countries. $^{81115}$

Additionally, rehabilitation may be offered by therapists without specialised knowledge of hand therapy ${ }^{16}$ Patient hands may be splinted with plaster of Paris slabs and the few who may be able to afford thermoplastic material opt for immobilisation or early passive mobilisation approaches. ${ }^{16}$ Limitations in therapists' expertise and resources (splinting material) combined with delayed or poorly repaired tendons are some of the factors that impact the execution of flexor tendon rehabilitation in accordance with the recommendations. ${ }^{12} 15$ There is evidence from Namibia, Botswana, Zambia, Zimbabwe and South Africa that tendon gliding exercises are introduced between 1 and 3 weeks following flexor tendon repair and not the recommended 3 days postoperatively. ${ }^{1811}$

Furthermore, low literacy levels in African countries may complicate rehabilitation as written instructions cannot be offered. The low ratio of therapist to patient in healthcare settings results in a reduced number of sessions per patient in relation to the recommended number of sessions. ${ }^{81113}$ Adherence to rehabilitation is further complicated by engagement in informal employment that is not supported by labour laws and policies and as such the notion of 'no work no pay' prevails. ${ }^{8} 13$ Patients may also intentionally default treatment, to ensure permanent disability or limitations following injury, in pursuit of a disability grant. ${ }^{17}$

Additional factors that impact flexor tendon rehabilitation within the African context directly relate to the nature of the condition. Many injuries seen in the African context may involve several structures in the hand that may contribute to severe oedema. ${ }^{16}$ Long-term presence of oedema leads to adhesion of structures and scarring that usually restrict tendon gliding. ${ }^{14}$ Limitations in wound management and infection control also contribute to poor outcomes following flexor tendon rehabilitation. ${ }^{11112}$

The outcomes following flexor tendon repair can be reported using the International Classification of Functioning, Disability and Health as a framework, and include aspects of body function and structure and activity and participation. ${ }^{1}$ Measures of body function and structure traditionally include the measurement of range of motion (ROM), total active motion (TAM), muscle strength, pain and oedema. Activity and participation is measured through either performance testing of hand function or 
through self-report measures such as the Michigan Hand Questionnaire or the Disabilities of the Arm, Shoulder and Hand Questionnaire (DASH).

The DASH is widely used in the African context despite being a less responsive self-report measure for measuring outcomes following flexor tendon rehabilitation. There are however many language versions of the DASH following translation and cross-cultural adaptation and it is freely available from the DASH website. ${ }^{148}$ It is however believed that more emphasis is placed on outcomes of aspects of body function and structure in African settings, and grip strength is often estimated due to unavailability of costly standardised assessment instruments. ${ }^{19}$

The above outlines the perceived contextual barriers that hinder flexor tendon rehabilitation and outcomes within the African context. The proposed scoping review will seek literature in an attempt to highlight contextual characteristics that might interfere with protocol implementation. It will also gather information on how these contextual differences influence flexor tendon management protocol applicability and outcomes.

\section{PURPOSE OF THE STUDY}

\section{Significance of the study}

Rehabilitation following flexor tendon injury and repair has evolved with research being undertaken to determine the best surgical and rehabilitative approaches. However, there is no consistent way of managing flexor tendon injuries in Africa due to over-reliance on adopted protocols from high-income countries. This scoping review will ascertain the types of flexor tendon rehabilitation protocols, feasibility and outcomes following implementation in African countries. Results could aid in reporting contextually relevant, cost-effective flexor tendon rehabilitation approaches that may yield improved outcomes in African countries.

\section{Aim}

This scoping review aims to identify, appraise and analyse research on rehabilitation protocols following flexor tendon injury in African countries.

\section{Objectives}

In an attempt to answer the research question and meet the aim of the study, the following objectives have been formulated:

1. To descriptively report on the incidence (number of cases) of flexor tendon injuries in African countries.

2. To descriptively report on surgical suturing of flexor tendons in African countries.

3. To identify the causes of flexor tendon injuries in African countries.

4. To report on the different types of flexor tendon rehabilitation approaches employed in African countries.

5. To report on the outcomes (including but not limited to ROM (active and passive), TAM of fingers, grip strength and hand function (through self-report or performance testing)) following flexor tendon rehabilitation in African countries.

6. To review factors that affect outcomes following flexor tendon rehabilitation in African countries.

7. To provide a narrative analysis of the literature to maximise findings in terms of clinical practice and research in flexor tendon rehabilitation in African countries.

\section{METHODS AND ANALYSIS}

This scoping review will be conducted under the methodological framework presented by Arksey and O'Malley and complemented by a description from Colquhoun et $a l^{20}{ }^{21}$ Arksey and O'Malley put forward a 5-stage process that dictates ways to find and analyse data to allow replication, rigour, transparency and reliability of findings. ${ }^{202}$ The methodological framework to be used in the scoping review process will follow the stages shown below:

- Stage 1: identifying the research question(s).

- Stage 2: identifying relevant studies.

- Stage 3: study selection.

- Stage 4: charting the data.

- Stage 5: collating, summarising and reporting the results.

\section{Stage 1: identifying the research questions}

Research questions linked to the objectives and aim of the study were developed to ensure that the scoping review will comprehensively identify and capture all types of literature within the scope of the topic..$^{202123}$

The research questions are as follows:

1. What is the number of cases of flexor tendon injury to the hand in African countries?

2. What surgical suturing of flexor tendons is performed in African countries?

3. What are the causes of flexor tendon injury in African countries?

4. Which approaches are used to rehabilitate flexor tendon injuries in African countries?

5. What are the outcomes of different rehabilitative approaches that are used to manage flexor tendon injuries in African countries?

6. Which factors affect outcomes following flexor tendon injury rehabilitation within African countries?

\section{Stage 2: identifying relevant studies}

The section will highlight probable evidence sources, strategies that will be used in searching for relevant literature and terms that will be employed in the process.

\section{Sources of evidence}

Potentially relevant literature will be identified in databases and a search strategy was developed through consultation with an expert librarian and refined by discussing with second and third reviewers. ${ }^{20}$ The following electronic databases will be searched from 1960 to date: Cochrane library, CINAHL-EBSCOhost, Academic Search Premier, Health Source Nursing (academic edition), Google Scholar, PubMed Medline, Scopus, Web of Science, 


\begin{tabular}{|c|c|}
\hline Topic & $\begin{array}{l}\text { "Flexor tendon injury" OR "flexor tendon injur" } \\
\text { OR "hand injury" OR "hand function" OR "finger } \\
\text { injury" OR "hand injur"” OR "finger injur"” OR } \\
\text { "finger function" OR "flexor tendon cut" OR } \\
\text { flexor tendon repair }\end{array}$ \\
\hline AND topic & $\begin{array}{l}\text { rehabilitation OR rehabilit* OR therap* OR } \\
\text { "occupational therapy" OR "physical therapy" } \\
\text { OR physiotherapy OR immobilis" OR immobiliz* } \\
\text { OR mobilis"” OR mobiliz" }\end{array}$ \\
\hline AND topic & Africa OR Afric* \\
\hline
\end{tabular}

African Journal Online, Sabinet African Journal, African Journal Archive and Africa-Wide. Further literature will be searched by screening the bibliography of the identified eligible articles. ${ }^{2021} 24$

Grey Literature Database of African Theses and Dissertation, WHO's OpenGrey and OpenDOAR, and university repositories will be explored. Researchers of discovered published articles and therapists interested in hand therapy will be contacted for any relevant flexor tendon injury papers. ${ }^{202}$

\section{Search strategy}

An initial search strategy was developed with assistance of an expert librarian following participants/concept/ context framework and will consist of search terms for the following characteristics:

1. Hand flexor tendon injury on adults who are 18 years or older.

2. Rehabilitation protocol: static immobilisation, early passive and early active mobilisation.

3. African continent.

List of terms

The following search string using the PubMed-suggested Medical Subject Headings terms (outlined for PubMed search in table 1 below) will be applied in each of the databases:

The initial screening was done with the assistance of the librarian to ascertain that searching falls within boundaries of the questions and limit unnecessary literature (see table 2 below). ${ }^{22}$

\begin{tabular}{ll}
\hline Table 2 Initial database screening results & \\
\hline Database & Results \\
\hline PubMed Medline & 62 \\
Sabinet online platform: & \\
$\quad$ Sabinet African Journal & 111 \\
African Journal Archive & 64 \\
CINAHL & 18 \\
\hline Africa-Wide Information & 34 \\
Academic Search Premier & 11 \\
Cochrane & 0 \\
\hline
\end{tabular}

Table 3 Provisional inclusion and exclusion criteria

\begin{tabular}{ll}
\hline Inclusion & Exclusion \\
\hline $\begin{array}{l}\text { Papers from } 1960 \text { to date (birth of } \\
\text { early active mobilisation(EAM)) }\end{array}$ & $\begin{array}{l}\text { Studies without surgical } \\
\text { technique }\end{array}$ \\
$\begin{array}{l}\text { The literature on zone II-V of } \\
\text { human hand flexor tendon injury } \\
\text { inclusive of nerve and other } \\
\text { additional injuries }\end{array}$ & $\begin{array}{l}\text { Biomechanical studies } \\
\text { only }\end{array}$ \\
$\begin{array}{l}\text { Studies conducted with adults (18 } \\
\text { years and above) }\end{array}$ & $\begin{array}{l}\text { Cases which have } \\
\text { undergone tenolysis }\end{array}$ \\
$\begin{array}{l}\text { Studies conducted in African } \\
\text { countries }\end{array}$ & $\begin{array}{l}\text { Studies only reporting } \\
\text { surgical technique or } \\
\text { approaches }\end{array}$ \\
$\begin{array}{l}\text { Studies reporting outcomes } \\
\text { of aspects of body function } \\
\text { and structure and activity and } \\
\text { participation }\end{array}$ & Animal studies \\
\hline
\end{tabular}

Studies with a flexor tendon

rehabilitation protocol

All languages

\section{Stage 3: study selection}

Eligibility criteria

The eligibility process has been developed as a guideline to select articles for the review. The focus is not strictly on the quality of studies; therefore, all manuscripts on flexor tendon rehabilitation that meet the criteria will be considered. ${ }^{25}$ The provisional inclusion and exclusion criteria are shown in table 3:

\section{Selection of sources of evidence}

To ascertain consistency and rigour, the researcher will use parameters stated in the above table to determine manuscripts suitable for the scoping review and relevant scripts will be managed using Covidence. The Covidence software will track included and excluded references to avoid duplication of articles. ${ }^{24}$ The first reviewer (principal investigator and first author) will appraise selected articles to verify if the contents meet the inclusion criteria. The first reviewer will read articles per consort format to align literature to research questions and objectives of the study. ${ }^{24}$ A second reviewer (second author) will check the inclusion eligibility of the captured literature by independently evaluating the title and abstract of articles. ${ }^{20}$ A third reviewer (third author) will be consulted for consensus when there is disagreement on the eligibility of any article. ${ }^{24}$ Thereafter, full-text screening of likely qualifying articles will be conducted to select papers that will be reviewed in the study by the first reviewer. The Preferred Reporting Items for Systematic Reviews and Meta-analysis Protocol flow chart will be included to illustrate the selection process. $^{22}$

\section{Stage 4: data charting process}

The first reviewer will read the full text of the selected articles. Excel program will be used to chart and organise relevant extracted data that meet the eligibility 
Table 4 Study timeline

\begin{tabular}{|c|c|c|}
\hline $\begin{array}{l}\text { Stage 1: identifying the } \\
\text { research question }\end{array}$ & 01 June 2019 & $\begin{array}{l}\text { Research questions have been created for the initiation and planning of } \\
\text { the scoping review protocol. }\end{array}$ \\
\hline $\begin{array}{l}\text { Stage 2: identifying relevant } \\
\text { studies }\end{array}$ & $20 \mathrm{~A}$ & $\begin{array}{l}\text { Searching strategy, database selection, and initial article searching have } \\
\text { been developed and run with the assistance of a librarian. }\end{array}$ \\
\hline $\begin{array}{l}\text { Stage 3: study selection/ } \\
\text { data collection }\end{array}$ & $\begin{array}{l}15 \text { Feb 2021-14 June } \\
2021\end{array}$ & $\begin{array}{l}\text { Provisional selection criteria have been formulated, but may change } \\
\text { when the review commences. We expect to screen } 300 \text { articles after } \\
\text { removal of duplication. The researcher will review } 19 \text { titles and abstracts } \\
\text { per week. A full-text review will commence on selected articles that met } \\
\text { the inclusion criteria. }\end{array}$ \\
\hline Stage 4: charting the data & $\begin{array}{l}15 \text { June } 2021-14 \text { July } \\
2021\end{array}$ & $\begin{array}{l}\text { On completion of stage } 3 \text {, charting will be initiated and } 30 \text { days have } \\
\text { been allocated for recording of research findings. }\end{array}$ \\
\hline $\begin{array}{l}\text { Stage } 5 \text { : collating, } \\
\text { summarising and reporting } \\
\text { results }\end{array}$ & $\begin{array}{l}15 \text { July } 2021-14 \text { Aug } \\
2021\end{array}$ & $\begin{array}{l}\text { A descriptive summary of the study findings will be conducted } 3 \text { weeks } \\
\text { after the completion of data charting. The scoping review will be } \\
\text { published so that the information can be disseminated worldwide. }\end{array}$ \\
\hline
\end{tabular}

criteria. Charting and update of key information from the reviewed article will be a continuous process. ${ }^{21}$ The following data will be extracted from the included studies: 1. Study characteristics: author names, publishing journal, published year, country of study and study population.

2. Study aims, objectives, research questions and study design.

3. Surgical suturing, protocol used, number of therapy sessions, ROM, TAM, muscle strength, pain level, oedema, activity and participation (Michigan Hand Questionnaire score, DASH score), harm outcomes (cases that referred for second operation or tenolysis).

A descriptive-analytical approach will be used as it enables the researcher to collect information, describe and explain characteristics centred around flexor tendon management in the African nations. ${ }^{26}$ Weft QDA, a qualitative data analysis system, will be used to analyse and categorise the literature into theme areas. The analysis will focus on extracting themes from the following areas:

- Nature of tendon injuries.

- Tendon rehabilitation approaches used.

- Outcomes of tendon rehabilitation.

- Factors that influence outcomes.

Data will be extracted on article characteristics based on the country name, tendon injuries, the protocol used, the outcome in terms of impairment, activity performance and participation, frequency of visit, a surgical procedure performed and complications encountered as follows:

- Characteristic (the protocol used, surgical procedure) of flexor tendon injury.

- Contextual factors that affect tendon rehabilitation and outcomes.

- Results in terms of TAM, activity performance and participation.

Stage 5: collating, summarising and reporting the synthesis of the results

The study findings will be grouped according to the protocol used, and data summarised about the population size, study type, and design and outcomes measured. ${ }^{21}$

\section{ETHICS AND DISSEMINATION}

No ethical clearance will be sought as the study is going to use secondary data. ${ }^{23}$ Information dissemination will consider two community theory approaches and social marketing dissemination framework. ${ }^{27}$ The theories and framework operate on the premise of collaborating relationships with policymakers and end-users. ${ }^{25} 27$ The researchers will, therefore, publish the article for other researchers and users, provide the script to associations of respective African countries, present the work, and discuss the paper with therapists and the policymakers aligned to the profession in African countries. ${ }^{13}$

\section{Patient and public involvement}

There was no patient or public involvement in the research.

\section{Timeline}

The proposed time frame for the study is described in table 4 .

Acknowledgements My gratitude goes to the librarian, Ingrid Van der Westhuizen, for her involvement in formulating a search strategy for this paper.

Contributors All three authors conceptualised, drafted, developed and edited the protocol in preparation for the scoping review. MM drafted the protocol script as part of his master's degree. SDK and L-AJ-NK assisted in protocol development and contributed several conceptual formulations and contributed to editing. All researchers contributed and are accountable greatly to the formulation of this script and will continue with the screening and extraction of data.

Funding The authors have not declared a specific grant for this research from any funding agency in the public, commercial or not-for-profit sectors.

Competing interests None declared.

Patient and public involvement Patients and/or the public were not involved in the design, or conduct, or reporting, or dissemination plans of this research.

Patient consent for publication Not required.

Provenance and peer review Not commissioned; externally peer reviewed.

Open access This is an open access article distributed in accordance with the Creative Commons Attribution Non Commercial (CC BY-NC 4.0) license, which permits others to distribute, remix, adapt, build upon this work non-commercially, and license their derivative works on different terms, provided the original work is properly cited, appropriate credit is given, any changes made indicated, and the use is non-commercial. See: http://creativecommons.org/licenses/by-nc/4.0/. 
ORCID iD

Martin Marume http://orcid.org/0000-0002-1188-8485

\section{REFERENCES}

1 Bal S, Oz B, Gurgan A, et al. Anatomic and functional improvements achieved by rehabilitation in zone II and zone $\mathrm{V}$ flexor tendon injuries. Am J Phys Med Rehabil 2011;90:17-24.

2 de Klerk S, Badenhorst E, Buttle A, et al. Occupation-based hand therapy in South Africa: challenges and opportunities. S Afr J Occup Ther 2016;46:10-14.

3 Ihekire O, Salawu SAI, Opadele T. Causes of hand injuries in a developing country. Can J Surg 2010;53:161-6.

4 Stewart A, Biddulph G, Firth GB. The aetiology of acute traumatic occupational hand injuries seen at a South African state Hospital. SA Orthop J 2017;16:49-53.

5 United Nations Department of Economic and Social Affairs (UN/ DESA), United Nations Conference on Trade and Development (UNCTAD), Economic Commission for Africa (ECA), Economic Commission for Europe (ECE) EC for LA and the, Caribbean (ECLAC), Economic and Social Commission for Asia and the Pacific (ESCAP) E and SC for WA (ESCWA)The UN, (UNWTO) WTO. World economic situation and prospects 2018 report [online], 2018. Available: https://www.un.org/development/desa/dpad/wp-content/ uploads/sites/45/publication/WESP2018 Full Web-1.pdf

6 Mayer J. Industrialization in developing countries: some evidence from a new economic geography perspective. Small Gr Res [online] 2004;7:73-98 http://ideas.repec.org/p/unc/dispap/174.htm

7 Reed D. Resource extraction industries in developing countries. J Bus Ethics 2002;39:199-226.

8 Buttle A. Introducing early active mobilisation following flexor tendon repair in a developing country context : a feasibility study. Stellenbosch University, 2018.

9 Seedat M, Van NA, Jewkes R, et al. Health in South Africa 5 Violence and injuries in South Africa : prioritising an agenda. Lancet 2009;374:61306-4.

10 Gordon T, Booysen F, Mbonigaba J. Socio-economic inequalities in the multiple dimensions of access to healthcare: the case of South Africa. BMC Public Health 2020;20:1-14.

11 Wentzel R, Van Velze C. Dissertation for the faculty of health sciences school of health care sciences a comparison of the outcomes of two rehabilitation protocols after flexor tendon repair of the hand at Chris
Hani Baragwanath academic hospital (protocol number:314/2014). University of Pretoria; 207AD.

12 Rigo IZ, Røkkum M. Predictors of outcome after primary flexor tendon repair in zone 1,2 and 3. J Hand Surg Eur Vol 2016;41:793-801.

13 Elliot D, Giesen T. Avoidance of unfavourable results following primary flexor tendon surgery. Indian J Plast Surg 2013;46:312.

14 Peter SE, Jhb B, Ross M. Rehabilitation following surgery for flexor tendon injuries of the hand (protocol). Cochrane Collab 2017:1:1-12.

15 Neiduski RL, Powell RK. Flexor tendon rehabilitation in the 21st century: a systematic review. J Hand Ther 2019;32:165-74.

16 Mncube NM, Puckree T. Rehabilitation of repaired Flexor Tendons of the Hand: Therapists' perspective. S Afr J Physiother 2014;70.

17 Mncube NM, Puckree T. Rehabilitation of repaired flexor tendons of the hand therapists' perspective. S A J Physiother 2014;70:33-8.

18 Braitmayer K, Dereskewitz C, Oberhauser C, et al. Examination of the applicability of the disabilities of the arm, shoulder and hand (DASH) questionnaire to patients with hand injuries and diseases using Rasch analysis. Patient 2017;10:367-76.

19 Kaisha WO, Khainga S. Causes and pattern of unilateral hand injuries. East Afr Med J 2008;85:123-8.

20 Arksey H, O'Malley L. Scoping studies: towards a methodological framework. Int J Soc Res Methodol 2005;8:19-32.

21 Colquhoun HL, Levac D, O'Brien KK, et al. Scoping reviews: time for clarity in definition, methods, and reporting. J Clin Epidemiol 2014;67:1291-4.

22 Munn Z, Peters MDJ, Stern C. Systematic review or scoping review ? Guidance for authors when choosing between a systematic or scoping review approach. BMC Med Res 2018;18:1-7.

23 Title ST. Preferred reporting items for systematic reviews and meta-analyses extension for scoping reviews (PRISMA-ScR) checklist:11-12.

24 Uys ME, Buchanan H, Van Niekerk L. Strategies occupational therapists employ to facilitate work-related transitions for persons with hand injuries: a study protocol for a scoping review. BMJ Open 2019;9:e027402.

25 Tricco AC, Lillie E, Zarin W, et al. Research and reporting methods prisma extension for scoping reviews (PRISMA-ScR): checklist and explanation. Ann Intern Med 2018;169:467-73.

26 Nassaji H. Qualitative and descriptive research: data type versus data analysis. Lang Teach Res 2015;19:129-32.

27 Wilson PM, Petticrew M, Calnan MW. Wilson_2010_disseminating research findings. Implement Sci 2010. 